\title{
PERSPECTIVAS DA FORMAÇÃO DE PROFESSORES PARA O MAGISTÉRIO NA EDUCAÇÃO BÁSICA: A RELAÇÃO TEORIA E PRÁTICA E 0 LUGAR DAS PRÁTICAS
}

\author{
Bernardete A. Gatti (FCC)*
}

\section{RESUMO}

Neste artigo analisamos questões relativas ao conceito de prática educacional e suas relações com as teorias, a partir de onde levantamos questões sobre as práticas desenvolvidas na formação para a docência na educação básica, seja em processos de educação continuada, seja em processos de formação inicial no ensino superior. A discussão parte da descrição de dois exemplos concretos realizados, um em escolas municipais de São Paulo, outro em uma Universidade Federal, em Niterói, a partir da utilização de publicações. Agregase estes exemplos de referências a várias outras iniciativas. Pelo examinado, considerando o universo possível para mudar e renovar perspectivas nessas formações, constata-se que as iniciativas ainda são tímidas: de um lado, não têm afetado substancialmente os currículos institucionais de formação para a docência em suas dinâmicas e práticas; de outro, nas formações continuadas ainda não alcançaram largo curso. No entanto, são reveladoras da consciência da necessidade de mudar práticas educacionais para essas formações e se mostram como alternativas pedagógicas ao hábito instaurado nos cursos de formação para a docência.

Palavras-chave: Prática educacional. Formação de professores. Educação básica.

\section{ABSTRACT}

\section{TEACHER EDUCATION: THE RELATIONSHIP THEORY - ACTION AND THE PLACE OF EDUCATIONAL PRACTICE}

In this article a conception of educational practice and his relations to theory are analyzed. Questions about educational practices in teacher education are arisen by the analyses of two innovative experiences: one in service, another in an initial course of teacher education. This two cases permit the elaboration of some analyses of policies in teacher education and point evidences about the weight of tradition and habits on the curriculum and didactic performances

\footnotetext{
Pós-Doutorado em Educação pela Universidade de Montreal (Canadá) e pela Universidade Estadual da Pensilvânia (Estados Unidos). Doutora em Psicologia pela Universidade de Paris VII (França). Pesquisadora Consultora do Departamento de Pesquisas Educacionais da Fundação Carlos Chagas (FCC). E-mail: gattibe@gmail.com
} 
in the formation practices of teachers. Other references of new experiences in this matter are mentioned. On observe that innovations in teacher education practices are very few in the waste universe of courses in the superior education level and in continued teacher education in the educational system. But they are evidence of the need of changes in this field.

Keywords: Educational practice. Teacher education. Basic education.

\section{RESUMEN}

\section{FORMACIÓN DE MAESTROS PARA LA EDUCACIÓN BÁSICA: LA RELACIÓN TEORIA-PRACTICA Y LA IMPORTANCIA DE LAS PRACTICAS EDUCATIVAS}

En este artículo se examinan los conceptos de practica y teoría en el campo de la educación e se analizan aspectos de las practicas en la formación de maestros para la docencia en la educación basica. Se trata de la formación de maestros en los cursos superiores así bien que sobre la formación contínua en las escuelas. Dos experiencias innovadoras son reportadas a partir de las cuales se analizan aspectos de las practicas y de las políticas de formación para la enseñanza en la educación básica. Otras referencias se hacen no que respecta a esas formaciones. Se analiza la dificultad de cambios en las formaciones para la enseñanza en la educación basica, con la consideración del peso de la cultura y de habitos en las practicas formativas. Las iniciativas innovadoras reportadas sinalizan bien la necesidad de cambios en las practicas educacionales.

Palabras clave: Practicas educativas. Formación de maestros. Educación básica.

\section{Introdução e conceitos}

A discussão sobre processos de formação para a docência adquiriu maior âmbito e profundidade nos últimos anos e variadas perspectivas despontaram quanto a eles, seus contornos e seus significados. Nas últimas décadas adquiriram relevo importante, na formação inicial para a docência, os aspectos teóricos relativos aos conhecimentos dos fundamentos da educação e das políticas, na perspectiva de superar a ênfase técnica que, particularmente nas décadas de mil novecentos e sessenta e setenta, teve forte presença nas formações, não só de professores mas em outras áreas também. 0 estudo de currículos dos cursos em que a formação para o magistério na Educação Básica é realizada ${ }^{1}$ nos vem mos-

1 Trata-se das diferentes licenciaturas, que abrangem as diversas áreas do conhecimento que compõem o currículo da educação básica, e também a licenciatura em pedagogia. trando que a formação em licenciaturas, em sua maior parte, tem caráter genérico e a ênfase nos conhecimentos de área específica ganhou predomínio nessa formação, com a consequente fragilização da preparação para o trabalho docente nas escolas com suas peculiaridades, fundamentos e práticas educacionais (GATTI, 2013, 2015; PIMENTA et al., 2017). Nesse contexto, a relação teoria e prática tornou-se objeto de debate em diferentes perspectivas. Muitas discussões emergiram e a busca de equilíbrio entre os dois tipos de formação acima apontados, e suas imbricações, começou a tomar corpo. Não se pode conceber a formação de docentes para o exercício do magistério na educação básica sem que se lhes ofereça boa formação teórica e cultural, mas, também, não se pode deixar de lado, associada a esta, uma formação para o trabalho educacional com as 
crianças, adolescentes e jovens no processo de aprendizagem escolar, o qual faz parte do desenvolvimento dos alunos como pessoas e cidadãos, papel fundante da educação básica. Formar docentes oferecendo-lhes cultura geral e especializada que lhes propicie a construção de uma filosofia educacional associada a uma praxiologia parece ser uma possível resposta aos dilemas enfrentados nas práticas formativas para a docência. Cito aqui a perspectiva traçada no artigo $2^{\circ}$.,$~ § 1^{\circ}$. da Resolução CNE/ CP no 02/2015, fruto de amplas discussões, e que significa uma síntese nessa direção:

Compreende-se a docência como ação educativa e como processo pedagógico intencional e metódico, envolvendo conhecimentos específicos, interdisciplinares e pedagógicos, conceitos, princípios e objetivos de formação que se desenvolvem na construção e apropriação de valores éticos, linguísticos, estéticos e políticos do conhecimento inerentes à sólida formação científica e cultural do ensinar/aprender, à socialização e construção de conhecimentos e sua inovação, em diálogo constante entre diferentes visões de mundo. (BRASIL, 2015, grifo nosso).

Na perspectiva das formações e considerando a dialeticidade do binômio teoria-prática/ prática-teoria, e a imbricação de ambos os termos, coloca-se como fundamental tanto mudar a concepção mais vigente sobre "prática" e "teoria" como opostos, como mudar a concepção de prática como mera aplicação direta de teorias aprendidas ou mediadas por técnicas, ou como mero uso mecânico de receituário de técnicas. Antropologicamente falando, as práticas educacionais são atos culturais realizados em um coletivo, portanto associadas a alguma teorização, elaborada ou não, mais consciente ou não, e embebidas de sentido. As práticas são ações socioeducacionais com fundamentos e escolhas. Elas se realizam nas múltiplas relações pedagógicas cotidianas entre educadores, docentes e alunos, na topologia escolar, em seus contornos ora mais definidos, ora mais fluidos, ora mais contínuos, ora com rupturas, ou, mais convergentes ou divergentes, com co- nectividade ou não, mudanças de direção etc. Pensar as práticas educacionais em contexto e em sua dinamicidade demanda a superação de uma concepção meramente simplista e técnica sobre o ensino, avançando para uma compreensão da unidade teoria-ação-relação-percepção-sensibilidade situacional-processo de escolha-comunicações-mudanças/ cristalizações. Elas podem envolver técnicas e tecnologias, mas, dinamicamente, estas são colocadas em prática com os sentidos do encaminhamento concreto das relações estabelecidas entre docentes e alunos, implicando dialogia. As técnicas e as tecnologias na sala de aula não falam por si, necessitam de interpretação. Mediações subjetivas ou intersubjetivas são efetivadas seja pelos estudantes, seja pelos professores, quando em contato com esses objetos e suas funções.

Assim, práticas educacionais implicam envolvimento, produzem motivação, alegrias, angústias, reações diversas em todos os envolvidos. Compreendê-las e discuti-las, como práticas relacionais humanas com intencionalidade específica, demanda perspectivas filosóficas, didáticas, pedagógicas, curriculares, psicossociais e educacionais amplas. Segundo Altet e Guibert (2014), a formação de professores requer, também, propiciar a construção de mudanças conceituais e de práticas, dado que as pessoas em formação para a docência já trazem seus próprios conceitos e representações sobre escola, ensino, aprendizagem, alunos, docência, avaliação etc. Se juntarmos essa ideia na perspectiva logo acima colocada, observamos que a questão da formação para a prática educacional é complexa, assim como é complexa a profissão docente, que ainda envolve aspectos subjetivos em maior grau que outras profissões e seus resultados por inteiro não podem ser traduzidos em medidas muito objetivas. Alie-se a isso as injunções do cenário, tanto próximo como mais amplo, em que nos tempos atuais estão imersas as escolas, as redes escolares, o trabalho dos professores, as práticas educativas. As práticas educacionais, que têm natureza 
essencialmente sociocultural, são afetadas pelos novos modos emergentes de vida social, do trabalho, novos valores, pelas vulnerabilidades sociais, tecnologias que estruturam aspectos do social, traços pessoais, lógicas e aprendizagens, com mudanças de expressões orais e escritas, das artes, e as novas simbologias. 0 desafio das formações para o magistério é, considerando essas questões e o avanço das ciências, como conduzir estudantes nas licenciaturas, na formação inicial, a construírem referenciais e modos de agir pedagógico para que crianças ou adolescentes se apropriem dos conhecimentos básicos considerados necessários à vida humana e social hoje e para um futuro próximo. Trata-se de, com visão desse contexto, saber trabalhar com práticas educacionais que deverão ser efetivadas nas atividades escolares, com aspectos dos conhecimentos, de tal forma que as crianças e jovens tenham a oportunidade, de fato, de apreender e interpretar esses conhecimentos. Como propiciar aos alunos o domínio da escrita e da leitura de modo que faça sentido e lhes permita criar sentidos, desenvolver lógicas e argumentos, comunicar-se com clareza, compreender bem o que está disponível como informação? Distinguir o essencial, o fundamento de algo proposto, o relevante do acessório? Como criar práticas educacionais que favoreçam aos estudantes compreender o fundamento da vida, as coisas relativas a este planeta, a este universo, à sua constituição? Práticas que possibilitem a compreensão e aprendizagens dessas questões e outras tantas que fazem parte do currículo das escolas, em cada nível escolar, em diferentes momentos do desenvolvimento psico-socioemocional das crianças, adolescentes e jovens? Só teorizar sobre essas questões não basta para o exercício do magistério. É preciso, no bojo de uma filosofia para o educar, saber fazer o acontecer aprendizagens. Assim, a questão das práticas educacionais na formação para a futura docência na educação básica abrange os dois universos: o que se pratica como formação nas licenciaturas e as condições de criação de práticas frutíferas para o futuro trabalho na educação básica.

\section{Inspirações em práticas formativas}

Vamos concretizar essas reflexões com a recuperação sintética, a partir de duas iniciativas das quais há publicações, de práticas formativas para o exercício do magistério, tanto em formação continuada como em formação inicial, em licenciatura, sobre as quais teceremos algumas considerações. Escolhi duas iniciativas que podem ilustrar bem os novos movimentos em práticas formativas para a docência, deixando claro que existem muitas outras que estão se colocando nos cenários educacionais. As apresentadas aqui o são a título de exemplo e inspiração para análises.

Começo fazendo uma breve narrativa - que não abarca a amplitude das ações realizadas - de experiência rara de formação continuada por pares, sem dirigismo oficial ou acadêmico, que nasceu em escola municipal de São Paulo - na zona sul, em área de grandes carências -, por um "empurrão" de uma coordenadora pedagógica que, já sendo educadora experiente, ao assumir essa função em escola pública, atentamente observando o trabalho na escola e a condição dos alunos dos primeiros anos do nível fundamental, perturbou-se e, no seu dizer:

Eu me encontrava tão desesperada e aflita que, na primeira reunião com o grupo de professores eu lhes disse: 'ninguém nunca escreveu e nem falou que o/a professor/a não ensina mais e os alunos não têm que aprender; este é o nosso compromisso, ensinar e promover a aprendizagem de todos.' (GARCIA, 2017, p. 2).

Fazem vinte e dois anos dessa atitude, que detonou, mesmo que com certa hesitação, uma parceria para um novo trabalho pedagógico, que envolveu as questões dos próprios professores, de um lado, e de outro, um melhor conhecimento das condições do alunado da região, desembocando em um projeto de formação, o PROVE, que acabou por envolver várias escolas 
da região. Até hoje, e com novos atores. Projeto dos educadores, nada a ver com a administração pública, que se mantém pelo envolvimento de todos das escolas e das comunidades. Movimento que a cada ano publica uma revista com artigos desses educadores falando e discutindo sobre suas práticas, em razão de necessidades nascidas nos cotidianos dessas escolas: "No PROVE, alunos e alunas/professores e professoras são sujeitos ativos da formação em que estão envolvidos e não meros objetos a serem modelados por não saberem o que devem saber e do jeito que lhes é ensinado." (GARCIA, 2017, p. 3). Mudanças grandes, permanência e continuidade do processo com novos coordenadores e professores, no tempo. Realização dos envolvidos e construção de valor para os docentes, para os aprendizes, todos aprendizes. Hoje, vinte e dois anos de sobrevivência de uma ação comunitária formativa, dezessete números da revista PROVE publicados, em que se tem uma boa ideia das práticas desenvolvidas, diz alguma coisa sobre os efeitos dessa opção de busca por formação em cooperação e participação coletiva. Mostra também que a emergência de lideranças variáveis e em diferentes aspectos põe movimentos diferenciados na proposta. Tendo como orientação do processo de formação a análise contínua das práticas e da realidade local e dos alunos, com aprofundamento teórico relativo às práticas, onde e como acontece e, "por este caminho vai se tornando possível, sem romantismo, a possibilidade de desvelar a peculiaridade dos estudantes das comunidades onde estão inseridas as escolas que integram o PROVE para serem devidamente consideradas, explicitadas, delineadas e trabalhadas." (GARCIA, 2017, p. 3). Então, “o não saber dos professores e professoras pode vir à tona não como algo a ser criticado e escondido, mas, pelo contrário, como portador de questões a serem problematizadas, analisadas, trabalhadas, compartilhadas" (GARCIA, 2017, p. 3). Assim, forma-se pelas relações entre os educadores, com contribuições mútuas, bem como recorrendo a outros profissionais que graciosamente contribuíram em momentos e aspectos específicos. A interação entre profissionais, nesse ambiente, gera "sentimento de pertencimento a um grupo de solidariedade, de afeto, de amizade, de compromisso." (GARCIA, 2017, p. 3-4). A revista, que é publicada anualmente, traz relatos de projetos desenvolvidos em escolas do grupo participante, socializando práticas e estimulando reflexões, onde se observa criatividade crescente e vínculo com questões atuais, locais e das próprias escolas. Um evento anual põe em relevo o realizado pelas várias escolas, docentes e alunos, e permite trocas fecundas. A título de ilustração, recupero alguns dos tópicos tratados nas formações construídas e compartilhadas pelos docentes e coordenadoras pedagógicas, nesses tempos e nesse percurso: questões da sala de aula - a escrita, a leitura, práticas de alfabetização, prática de trabalho em várias disciplinas (por exemplo, geografia, educação física etc.), a prática da interdisciplinaridade, questões do meio ambiente, aprendizagem com tecnologias, a escrita, texto e gramática, materiais concretos e jogos no ensino da matemática, redação de textos autorais, as perguntas no ato de aprender; práticas restaurativas, conhecendo o aluno com deficiência: práticas possíveis, oficinas da EJA-revisões, e tantos outros. Temas mais gerais que emergiram das escolas: "Nós e os outros: por que as diferenças incomodam tanto?"; "A sala de aula como objeto de pesquisa: relato e análise da prática"; "Reconstruindo as relações étnico-raciais na sala de aula"; "A dança na escola"; "Olhares sobre a adolescência num perspectiva: adulto $\mathrm{X}$ adolescente, adolescente X adolescente"; "Resolução de situações-problema em sala de aula." E muito mais. Na Apresentação da Revista PROVE - novembro de 2018, lê-se: "Não é sem razão que a frase-tema do seminário de 2014: 'Os desafios do PROVE na formação do educador: amorosidade, dedicação, coragem, ousadia na escola pública' está aqui sendo lembrada." Esta frasetema "continua sendo nosso grande desafio e, apesar dos momentos de muita ansiedade e 
apreensão, ao final, mais um número da revista para apreciação de nossos assíduos leitores." (GRUPO DE ESCOLAS MUNICIPAIS DO ENSINO FUNDAMENTAL DA CIDADE DE SÃO PAULO, 2018). Uma experiência cooperativa.

O que uma iniciativa como essa nos sinaliza? 0 primeiro aspecto a ressaltar é a valorização dos educadores das próprias escolas - nós podemos fazer nossa própria formação, decidir sobre as necessidades, como buscar conhecimento e construir e reconstruir práticas educativas e, também, se convidamos ou não alguém externo para nos ajudar, quando e em relação a quê. 0 segundo aspecto é o envolvimento e o necessário compromisso coletivo que se renova temporalmente. A experiência descrita conta com a participação ativa, contínua, de docentes, coordenadores(as) pedagógicos(as), diretores(as) e alunos (as) com foco em necessidades reais levantadas por eles em coparticipação interessada. Aparece o "preciso" e o "quero, sim". Implica também em envolvimento dos pais e comunidade onde, como e quando relevante para todos. Para tanto, a gestão da escola abre-se a essa proposta, incentiva, cria espaços e tempos para as ações, abre-se até mesmo para a quebra de algumas imposições burocráticas da gestão da rede. Assume atitudes e responsabilidades que a Lei de Diretrizes e Bases da Educação Nacional (BRASIL, 1996) - lei maior - lhes assegura (e que gestões governamentais esquecem que lá estão).

Uma prática que constrói autonomia profissional, de fato, não de discurso. Criada pelos educadores no exercício de suas atividades, em movimento coletivo tão difícil em razão dos parâmetros pré-definidos da vida escolar e dos hábitos tão bem aí instaurados, permite o lidar com as dificuldades de professores e alunos com a confiança de que todos buscam algo comum: a melhoria de suas condições como docentes e a aprendizagem mais efetiva das crianças e dos adolescentes e jovens. É um aprendizado desigual, de cada um, e que bom! Cada um com suas mediações e a sua identidade como professor - educador que constrói e se apropria de referentes próprios, abrindo o leque para escolha em situações variadas e de modos de atuar educativamente onde estão e com quem estão. E, com a coparticipação, ter a certeza de contar com outros para dividir dúvidas e angústias, buscando conhecimentos e soluções. Permite o exercício do refrão tão típico na nossa cultura musical: "oi abre alas, que eu quero passar..." Eu sou, nós somos, nós fazemos e acontecemos.

Outro ponto importante é que essa proposta nasceu e caminha na contramão da história das formações continuadas de professores no Brasil, em que essas formações, na maioria dos casos, são iniciativas de governos - central, regionais ou locais -, ou de associações, ou de organizações não governamentais, com formato e conteúdos pré-definidos, na pressuposição de que é exatamente daquilo que os professores precisam. Quando não, oferta de conteúdos para doutriná-los apenas. Nessas condições, mesmo com adesão voluntária dos docentes (o que nem sempre é o caso), não se pode assegurar interesse e correspondência a necessidades ou buscas desses docentes, bem como seu envolvimento de fato com a formação oferecida. E, mais ainda, nada assegura efeitos nas práticas educacionais, ou sequer efeitos para a melhor qualidade das aprendizagens dos alunos.

Nossa cultura política monolítica e centralizadora, construída em nossa história social, em que hegemonias de vários tipos disputaram e disputam espaço mas, com um mesmo traço - o mito do salvador ou salvadores - tão perene entre nós, o qual cria simulacros de participação e retira a possibilidade real de coparticipação, de criação e ação responsável dos que de fato estão na lida cotidiana do trabalho escolar; inibe a emergência de iniciativas dos que têm os problemas de aprendizagem das novas gerações diante de si, a cada dia; gera passividade e a atitude de espera que alguém do governo, ou enviado por ele, venha resolver os impasses, as situações que emergem e propiciar cursos salvadores. Cria atitude de 
"nada posso fazer" ou "tenho que fazer como mandam". Ao contrário, nas políticas de gestão direta, por que não incentivar e criar ambiência para o desabrochar de atitudes criativas, confiar nos educadores das redes, mesmo na consciência de limitações eventualmente existentes, apoiá-los, acompanhá-los, ajudá-los com suportes solicitados quando necessários? Por que formatar, sempre? Por que não se tenta atitudes novas, sair do modelo de dar regras e prescrições estritas para as práticas docentes, com pré-julgamentos? Buscar outras formas diferentes da entrega de conhecimento pronto. Aí, sim, exercer uma gestão democrática, com balizas flexíveis e transparentes, visando abertura para heterogeneidades e diferenciais entre as escolas. Se o modelo mais comum de gestão e formas de realização atual das formações tivesse efeito importante, não teríamos a situação educacional que temos, com tantos problemas, porque projetos e programas de formação de docentes e gestores é o que não nos faltou nesses últimos trinta anos, com alto custo orçamentário (GATTI et al., 2019).

É importante sinalizar que variadas outras iniciativas em formação continuada de professores, sinalizando novas práticas, vêm se mostrando no cenário educacional, abrindo para novas perspectivas em práticas educacionais, como se pode constatar, por exemplo, entre vários outros, nos trabalhos de Albuquerque, Frison e Porto (2014), de Aikawa e Gonzaga (2015), de Carvalho e Fiorentini (2015) e do município de Canoas (2018).

Iniciativas também podem ser destacadas na formação inicial em licenciaturas, as quais evidenciam novas perspectivas florescendo com a preocupação relativa às práticas pedagógicas. São propostas que objetivam alterar dinâmicas pedagógicas em disciplinas curriculares, algumas que saem da esfera do campus e articulam ações com escolas, envolvem educadores da educação básica em cooperação, gestores também, conduzindo os licenciandos a experiências diversificadas, desenvolvidas em coparticipação para criar ambiências de apren- dizagens significativas para os alunos da escola, que também vivenciarão de modo participativo as ações pedagógicas propostas com intencionalidades claras. São exemplos dessas ações o que se pode observar nos relatos de Sarti (2013), ou de Fuzer (2017), de Ruas (2017), ou em Ramos, Hoffmann e Razzera (2019), entre tantas outras espalhadas pelo país, mas que se constituem em iniciativas pontuais, que podem perecer sem frutificar amplamente, na medida em que muitas são desenvolvidas sem apoio institucional ou de um coletivo consciente de uma meta formativa de consenso.

Como no primeiro caso relatado, escolhemos outra experiência, que é tomada a título de exemplificação para reflexão, representando o que se tem verificado como novas ações que emergem na formação para a docência. 0 trabalho do grupo PET - Conexões de Saberes, da Universidade Federal Fluminense (UFF), é relatado em livro organizado por Vasconcelos e Andrade (2019), contemplando exposições e análises dos participantes dos projetos interdisciplinares desenvolvidos com escolas na perspectiva de "uma outra escola". 0 relato e as análises referem-se ao trabalho realizado entre 2015 e 2017. A ideia-mãe de todo o trabalho está colocada na apresentação do livro citado, onde está posto que se entende a escola "como espaço potente para a problematização, revisão e ampliação de conhecimentos, por meio da propositura e da solução de problemas que, de fato, sejam instigantes e enriquecedores, para os jovens e as crianças" (VASCONCELOS, 2019, p. 1). Isto pressupõe desenvolver "práticas que considerem a curiosidade, a observação em articulação com análises constantes, estudo contínuo, trabalho em colaboração, respeito mútuo, solidariedade e humildade" (VASCONCELOS, 2019 , p. 2). Toda ação educacional é realizada em cooperação ativa de todos os segmentos envolvidos, inclusive os alunos da escola. A aproximação com as escolas foi realizada com delicadeza e respeito. A preparação é intensa e bem trabalhada na busca de uma construção coletiva de caminhos metodológicos e mate- 
riais de apoio didático. São apresentados quatro projetos interdisciplinares realizados em duas escolas estaduais, os quais são fundamentados, descritos e analisados (VASCONCELOS; ANDRADE, 2019). São tecidas considerações sobre as metodologias acionadas pelos vários autores-atores, refletindo sobre as diferentes formas do trabalho educacional desenvolvido. Os temas escolhidos pelos alunos-turma da escola foram: jogos eletrônicos, música, outras culturas, gastronomia e grafite. Foram trabalhados com as propostas coletiva e participativamente elaboradas, planejadas e desenvolvidas, como segue: "Projeto Gamecrático", envolvendo as disciplinas: Língua Portuguesa (produção textual) e História; "Projeto Que som é esse?", trabalhado com as disciplinas Arte, História e Língua Portuguesa; "Projeto Aulas sem leis", trabalhado com as áreas de Língua Portuguesa e Literatura, História, Matemática e Tema Transversal (Pluralidade Cultural); "Projeto Da cozinha à rua, vidas que têm voz", que envolveu as áreas de Geografia, História, Matemática, Língua Portuguesa e os temas transversais Trabalho e Consumo, Pluralidade Cultural, Ética e Orientação Sexual.

0 que se percebe com o trabalho educacional realizado e as próprias considerações tecidas pelos diferentes grupos que se envolveram com os projetos? Evidenciam envolvimento motivado, imersão intensa dos licenciandos com as questões do magistério, presença constante e participante dos docentes envolvidos, capacidade de ajustar direções no processo, capacidade de superar obstáculos, imersão nos conteúdos necessários ao trabalho interdisciplinar, aperfeiçoamento de práticas e de expressão oral e escrita, consideração pelo conhecimento do outro, capacidade de cooperar, lidar com as diferenças, de mudar. A construção de ambiente de um grupo de trabalho em que há segurança para se recorrer uns aos outros, onde se aprende sem constrangimento a rever encaminhamentos, criou um clima de real cooperação em prol do desenvolvimento pessoal e profissional de todos os estudantes e o compromisso ético com a aprendizagem dos alunos da escola numa perspectiva de educação integral: conhecimentos inter-relacionados de conteúdos, com seus sentidos sociais.

Poderíamos citar muitas outras iniciativas que assumem características de mudança na perspectiva de práticas formativas para o exercício da docência, para os que estão em formação, integrando docentes do ensino superior e da escola, licenciandos, alunos da escola, em várias áreas disciplinares (BASTOS; NARDI, 2018; IZA; SOUZA NETO, 2015; MARTINS; ZAPPONE, 2018; NORBERG, 2017). O Programa Institucional de Bolsa de Iniciação à Docência (PIBID), proposto pelo MEC/CAPES em 2008, suscitou muitos projetos integradores, nas licenciaturas, com novas práticas educativas para formar para a docência na educação básica, envolvendo escolas, professores e alunos desse nível educacional. Há disponibilidade de muitos relatos de estudos sobre o realizado nesse programa e sobre suas contribuições a práticas pedagógicas (GATTI et al., 2014; SILVA; RIOS, 2019). Muitas outras coletâneas apresentando iniciativas de práticas realizadas nas formações iniciais para a docência foram publicadas nos últimos anos, testemunhando a busca de alternativas formativas para o preparo do exercício da docência na educação básica em diferentes áreas disciplinares (KRONBAUER; SIMIONATO, 2012; MARTINS; MOMOLI; BONCI, 2018). 0 mesmo ocorre com experiências de formação continuada em que novas ideias e práticas são experimentadas (CALDERANO; MARQUES; MARTINS, 2013). Interessante é notar os variados referenciais teóricos em que essas iniciativas se apoiam, trazendo uma riqueza de perspectivas.

André (2016) organizou livro em que apresenta pesquisas de diferentes autores que revelam práticas que são caracterizadas como inovadoras tanto na formação inicial como na continuada. Em Gatti e outros (2019) há relatos e análises de várias iniciativas que inovam, em alguns aspectos, práticas formativas em licenciaturas e realizadas por setores de governo. 
Cabe observar que as experiências de novas práticas na formação para o magistério nas licenciaturas não se mostram como alterações de perspectivas curriculares e dinâmicas formativas para o curso como um todo, mas são iniciativas de um ou vários docentes em aspectos particulares do currículo - em uma dada disciplina ou no estágio curricular - e sua continuidade depende de circunstâncias que se associam à carreira do docente ou à continuidade de apoios dos quais a iniciativa necessita. Quando se trata de formações oferecidas por secretaria de educação, a proposta, em geral, está atrelada a um período de governo, o que dificulta a consolidação de políticas mais duradouras, que são as que revelam possibilidades de consolidação de novas práticas. Com as trocas de governo, em qualquer dos níveis, não fica assegurada essa consolidação com efeitos transformadores em razão da descontinuidade de ações. Há nos que trabalham nessas secretarias a preocupação constante sobre continuidade ou não das ações na ocorrência de eventual mudança de gestão (decorrente de eleições ou troca de secretários em uma mesma gestão), o que gera ansiedades e até, em casos extremos, descompromisso e descrença, o que tem seus efeitos nas práticas.

Têm surgido, também, estudos sobre novas formas de desenvolver práticas formativas de formadores de professores, revelando preocupações com a formação dos docentes do ensino superior justamente para a prática da docência nesse nível, e prática para formar para o magistério na educação básica. Preocupação recente que vem ganhando espaço nos debates acadêmicos e em ações de gestão com a implementação, por exemplo, dos mestrados profissionais que têm foco na formação de professores formadores de docentes (PASSOS, 2018; SANCHES; PASSARELLI, 2019).

Mesmo com toda a contribuição que novas propostas em práticas formativas de docentes realizadas no país em diferentes recantos, áreas de conteúdo, condições e níveis de ensino, elas revelam, nas formas em que são propostas, um traço de nossa história sociocultural no que diz respeito à formação de professores para a educação básica - a dificuldade de permanência temporal. ${ }^{2}$ Em âmbito mais amplo, na história da formação de professores no país é constatada a trajetória inconstante das propostas de formação de docentes para a educação básica por parte de órgãos governamentais e, muito particularmente, para os primeiros anos do ensino fundamental e para a educação infantil, decorrente de uma tradição de políticas que não se mostram como políticas de Estado, mas como políticas deste ou daquele governo, deste ou daquele grupo de poder ou grupo hegemônico (GATTI; NUNES, 2009; GATTI et al., 2019; TANURI, 2000).

\section{História, cultura e práticas}

Permitam-me adentrar um pouco na história relativa à formação de professores, muito sinteticamente, uma vez que essa história é reveladora de práticas para essa finalidade. Os desafios que hoje são constatados pelas pesquisas no que se refere a práticas formativas de docentes para a educação básica abrangendo tipo de curso, currículos, culturas institucionais, formação dos professores do ensino superior que atuam em licenciaturas, metodologias abraçadas etc. - foram historicamente construídos em um caldo de cultura que, desde a Colônia, marcou os passos da escolarização do povo brasileiro e da formação de seus professores. Considerar esse caminhar faz-se necessário porque traços culturais têm permanência no tempo e condicionam práticas sociais e educacionais. Também consideramos, como Mainardes (2006), que a relação das políticas que pretendem regular ou orientar as ações educacionais são objeto de interpretações e mediações diversas dos atores que concretizam as práticas educativas em contextos diversos e, nos termos desse autor, isso nos leva a considerar "processos de resistência, acomodações,

2 Lembramos aqui as lutas para a manutenção pelo Ministério da Educação do PIBID, em 2015 e 2017. 
subterfúgios e conformismo dentro e entre as arenas da prática, e o delineamento de conflitos e disparidades entre os discursos nessas arenas" (MAINARDES, 2006, p. 50).

No período do Brasil Colônia, Portugal, a Metrópole, mostrou interesse apenas em explorar as riquezas da nova terra, e o que se teve como escola "de primeiras letras" foram iniciativas esparsas, na maior parte para atender ao que se poderia chamar de elite local. Assim como a escolarização da população em geral não era cogitada, era esparsa e precária em sua maior parte, o movimento de institucionalização de escolas para formação de professores veio a se mostrar somente no século XIX. Instalou-se a prática do ensino mútuo, ou método Lancaster, em que alunos mais adiantados eram instruídos por um professor e depois passavam a formar outros alunos. Com um professor era possível formar várias turmas de reprodutores de conhecimentos, pois esse ensino era baseado na repetição e memorização apenas. Com isso pouco recurso era necessário. Quando, no Brasil em 1827, se instalou a figura do professor adjunto, foi adotado esse tipo de formação, que deveria ser pago com seus próprios recursos. Uma forma bem prática, realizada em curto prazo. Não houve a expansão esperada com esse modelo de prática, sem incentivos e interesse das províncias. Então, mais adiante sobreveio a criação das primeiras escolas normais. As chamadas escolas normais, para formar professores para o ensino das "primeiras letras", tiveram instalação com fundações e extinções sucessivas, dependendo dos interesses de governos locais. As fontes históricas mostram criação de escolas normais por um período e sua extinção em sucessão rápida pela pouca procura (falta de pessoal com condições de estudo), mal funcionamento ou desinteresse de governos locais. Elas oscilaram também pela oferta ora de formação meramente prática, como treinamento de técnica de ensino, ora de formação apenas teórica, na ideia de que esta seria suficiente para se dar aulas. Escolas efêmeras, apostas ao primário, que no dizer do
Presidente da Província do Paraná, em 1876, eram como "plantas exóticas: nascem e morrem quase no mesmo dia." (MOACYR, 1940, p. 239). Conforme análises de Tanuri (2000, p. 65), "Pode-se pois dizer que nos primeiros 50 anos do Império, as poucas escolas normais do Brasil, pautadas nos moldes de medíocres escolas primárias, não foram além de ensaios rudimentares e malsucedidos."

Com o movimento pela proclamação da República, no final daquele século, as ideias liberais de democratização e obrigatoriedade do ensino primário aparecem na cena, mas a Primeira República acabou por não favorecer a expansão da escolaridade básica e, consequentemente, a formação de professores. Terminamos o século XIX com apenas quatro escolas normais. Adentramos o século XX com oferta de escolas bem reduzida ante o crescimento da população. A expansão da educação básica só vai começar a se efetivar em termos nacionais a partir de meados dos anos mil novecentos e cinquenta (GATTI; SILVA; ESPÓSITO, 1990). Essa expansão já vinha mostrando sinais em alguns poucos estados, e, com ela, a expansão das escolas normais agora em nível secundário, constituindo-se, em uma primeira fase, com currículo distribuído entre formação geral e formação em práticas para o magistério dos anos iniciais. As escolas normais representaram no século $\mathrm{XX}$, por um período, um grande avanço nas práticas dirigidas à formação de professores para os primeiros anos do ensino fundamental. No entanto, é preciso considerar que em termos de país as desigualdades regionais eram muito acentuadas. Tanto que, em uma visão geral dada pelo Censo Escolar realizado em 1964, somente $56 \%$ dos professores em exercício no curso primário, da $1^{\mathrm{a}}$ à 4⿳a série à época, possuíam curso de formação para a docência. Entre os demais, professores leigos, 72\% tinham apenas o curso primário e uma parcela deles, primário incompleto (BRASIL, 1967).

Para lecionar no nível secundário, predominou no século XIX e início do século XX a 
admissão como professores de pessoas cultas em alguma das áreas disciplinares. Apenas em 1938 é que se instituíram as licenciaturas para as disciplinas do secundário, na forma de um ano de formação atrelado aos bacharelados, e em seguida, o curso de pedagogia para a formação de especialistas em educação. Pouca preocupação curricular é evidenciada com os cursos de licenciatura para disciplinas específicas até o ano de 2002, quando é aprovada a Resolução CNE no 01/2002, sobre diretrizes para a formação de professores em nível superior (BRASIL, 2002), em que a questão das práticas pedagógicas para a docência são tratadas, inclusive tendo sido propostas as horas de prática como componente curricular, ideia retomada pelo CNE em 2015 (BRASIL, 2015). Retomada porque os termos da resolução de 2002 acabaram por não ser implementados. Poucos estudos e debates foram realizados sobre as práticas curriculares e as dinâmicas formativas nas licenciaturas. Por bom período tudo se passa como se essas práticas fossem as ideais. Na última década é que essa questão começou a ser problematizada e se começa a apontar o desequilíbrio nesses cursos entre formação teórica e formação em metodologias e práticas de ensino, com a tendência de predomínio da primeira em detrimento da formação para as práticas demandadas pelo exercício do magistério nas escolas. As próprias práticas formativas desenvolvidas pelos docentes no ensino superior, nas licenciaturas e outros cursos começam a ser discutidas. 0 debate não é simples, pois o temor da volta a um tecnicismo sem fundamento nas formações está presente na cultura educacional e é ponto importantíssimo para ponderação. No entanto, não é possível negar a necessidade de discussão das práticas formativas nesses cursos. Práticas concebidas como colocado no início deste artigo. Com currículos institucionais que se tornaram cada vez mais genéricos, alguns fortes apenas nos conteúdos específicos de áreas, outros mais aligeirados, estágios sem projeto e acompanhamento e monitoramento claros, levaram a questionamentos quanto ao que se pratica nas licenciaturas, em suas salas de aula, em suas atividades como formação para a docência na educação básica, e se essas práticas correspondem à projeção dos cenários socioculturais, ao avanço das ciências e dos conhecimentos didático-pedagógicos, das relações comunicacionais, da necessidade de superação das carências constatadas especialmente pelas pesquisas com egressos e com professores iniciantes (PAPI; MARTINS, 2010; UMBELLINO; CIRÍACO, 2018)

Nas contingências dos cotidianos persiste a preservação do tradicional, como espécie de âncora, mas também irrompem práticas, como relatamos antes, que buscam caminhos novos para formar para as práticas educacionais com crianças e jovens, mudando perspectivas, partindo da imersão no concreto escolar para a construção de novas maneiras de propiciar amor pelo conhecimento, busca de conhecimento, construção de aprendizagens para os envolvidos ou que se envolverão futuramente com formações de pessoas ou profissionais. Trata-se de processos de socialização e educação contínuos - dos próprios docentes do ensino superior com os licenciandos, os docentes com que passam a conviver e cooperar na escola, os alunos das escolas -, com suas aprendizagens, formas de pensamento e linguagens, valores e modos de ser, crenças e comportamentos, mediações intrincadas. Tudo isso sujeito a circunstâncias. É processo relacional mútuo, intencional, fundado em práticas colaborativas. Se estas práticas que rompem com modalidades reificadas de tratar a formação para a docência vão ter largo curso, ampliar-se para projetos de cursos inovadores em relação ao praticado, só o tempo nos dirá.

\section{Questões que ficam}

Práticas educacionais que representam novas buscas sobre como desenvolver formação para o magistério na educação básica são tratadas em bibliografia que começa a se avolumar. 
No entanto, resta saber se a socialização dessas experiências em publicações de natureza variada tem sido buscada para referenciar disciplinas curriculares nos cursos de formação de professores. Qual o grau de desconhecimento dessas produções? 0 quanto se tem inovado em referências que dizem respeito às questões de didática e das práticas de ensino? Fica a pergunta: qual o impacto desse conhecimento, dessa literatura, sobre práticas nos currículos de formação de professores? As referências são utilizadas para estudo e orientação de novas práticas formativas de professores? Para análises, criticas e reconstruções? Práticas educativas desenvolvidas nas instituições formadoras de professores no âmbito de programas como o PIBID ou da Residência Pedagógica foram incorporadas aos processos curriculares das várias licenciaturas em termos mais amplos? São conhecidas, discutidas, no âmbito do corpo docente das próprias instituições? 0 conhecimento advindo sobre práticas interessantes ao desenvolvimento de aprendizagens tem sido apropriado para o planejamento dos estágios curriculares obrigatórios? Qual o grau dessa apropriação? Uma última questão: docentes que atuam em uma mesma licenciatura conversam entre si, como um coletivo, sobre suas práticas educacionais?

Estamos falando de impactos em um amplo universo de docentes que atuam nas licenciaturas, que, segundo o Censo da Educação Superior 2018, perfazem um total de 7.415 cursos, onde $37 \%$ dos matriculados estão em instituições públicas e 63\% em instituições particulares (INEP/MEC, 2018). 0 acervo de conhecimentos que dispomos renovando propostas de práticas educacionais parece ainda encontrar pouco espaço nesse âmbito, se considerarmos as análises já citadas. Nos traços ainda perceptíveis de nossa cultura, no que se refere à formação para a docência na educação básica, iniciativas de mudanças com relação a perspectivas formativas meramente reprodutivas, embora ainda poucas nesse universo, representam tentativas de ruptura de uma tradição cujo peso é considerável. A burocracia instaurada e introjetada, os hábitos e crenças reificados sob diferentes formas, atuam preferentemente na perspectiva da conservação e controle de práticas curriculares, dificultando rupturas e diversificação de ações curriculares e pedagógicas. No entanto, há movimentos nesse espaço que sinalizam novas perspectivas, como exemplificamos, e que se mostram um movimento cultural que inova e procura responder a angústias experimentadas por formadores quanto às práticas educacionais para a educação básica, em cenário social heterogêneo e mutante.

\section{REFERÊNCIAS}

AIKAWA, M. S.; GONZAGA, L. T. Programa de tutoria educacional: uma experiência inicial de formação continuada em serviço. In: CONGRESSO NACIONAL DE EDUCAÇÃO - EDUCERE, 12., 2015, Curitiba. Anais [...]. Curitiba: PUC/PR, 2015. Disponível em: http://educere.bruc.com.br/ arquivo/pdf2015/15962_9613.pdf. Acesso em: 25 out. 2019.

ALBUQUERQUE, M. P.; FRISON, L. M. B.; PORTO, G. C. Memorial de formação escrito no decorrer da prática docente: aprendizagens sobre alfabetização e letramento. Revista Brasileira de Estudos Pedagógicos, Brasília, DF, v. 95, n. 239, p. 73-86, 2014.

ALTET, M.; GUIBERT, P. Construire un curriculum européen a partir de l'observation et l'analyse des pratiques enseignantes. In: PASQUAY, L. et al. (org.). Travail réel des enseignants et formation. Louvain-la-Neuve: De Boeck Supérieur S.A, 2014. p. 79-96.

ANDRÉ, M. E. D. A. (org.). Práticas inovadoras na formação de professores. Campinas, SP: Papirus, 2016.

BASTOS, F.; NARDI, R. (org.). Formação de professores para o ensino de ciências naturais $e$ matemática: aproximando teoria e prática. São Paulo: Escrituras, 2018.

BRASIL. Ministério da Educação. II Conferência Nacional de Educação: 1966 - Porto Alegre. Brasília, DF: MEC/INEP, 1967.

BRASIL. Presidência da República. Casa Civil. Lei no 9.394, de 20 de dezembro de 1996. Estabelece as 
diretrizes e bases da educação nacional. Brasília, DF, 1996. Disponível em: http://www.planalto.gov.br/ ccivil_03/leis/19394.htm. Acesso em: 04 nov. 2019.

BRASIL. Ministério da Educação. Conselho Nacional de Educação. Resolução CNE/CP no 1, de 18 de fevereiro de 2002. Institui Diretrizes Curriculares Nacionais para a formação de Professores da Educação Básica, em nível superior, curso de licenciatura, de graduação plena. Brasília, DF: MEC/ CNE, 2002.

BRASIL. Ministério da Educação. Conselho Nacional de Educação. Resolução CNE/CP no 2, de 01 julho de 2015. Define as Diretrizes Curriculares Nacionais para a formação inicial em nível superior (cursos de licenciatura, cursos de formação pedagógica para graduados e cursos de segunda licenciatura) e para a formação continuada. Brasília, DF, 2015. Disponível em: http://portal.mec.gov.br/ docman/agosto-2017-pdf/70431-res-cne-cp-00203072015-pdf/file. Acesso em: 10 out. 2019.

CALDERANO, M. A.; MARQUES, G. F. C.; MARTINS, E. B. A. (org.). Formação continuada e pesquisa colaborativa: tecendo relações entre universidade e escola. Juiz de Fora, MG: Editora UFJF, 2013.

CANOAS (RS). Diretoria Pedagógica. Saberes em diálogo, docência, pesquisa e prática pedagógica. Seminário Municipal. Apresentação em powerpoint. Canoas, RS, 2018.

CARVALHO, D. L.; FIORENTINI, D. Refletir e investigar a própria prática de ensinaraprender matemática na escola. In: CARVALHO, D. et al. (ed.). Análises narrativas de aulas de matemática. São Carlos, SP: Pedro \& João Editores, 2013. p. 51-63.

FUZER, C. Leitura e avaliação de textos: etapas para a formação inicial de professores de produção textual. Textos FCC, São Paulo, v. 53, p. 10-51, 2017.

GARCIA, O. G. PROVE: 20 anos - o reconhecimento do valor de professores e professoras, como princípio orientador de uma proposta de formação do educador. Revista do Projeto de Valorização do Educador e Melhoria da Qualidade de Ensino - PROVE, São Paulo, Ano 16, n. 16, p. 2-4, nov. 2017.

GATTI, B. A. Educação, escola e formação de professores: políticas e impasses. Educar em Revista, Curitiba, n. 50, p. 51-67, 2013.

GATTI, B. A. Formação de professores: compreender e revolucionar. In: SILVA JÚNIOR, C. A. et al. (org.). Por uma revolução no campo da formação de professores. São Paulo: Editora UNESP, 2015. p. $229-243$.
GATTI, B. A.; NUNES, M. M. R. (org.). Formação de professores para o ensino fundamental: estudo de currículos das licenciaturas em pedagogia, língua portuguesa, matemática e ciências biológicas. São Paulo: Fundação Carlos Chagas, 2009. (Coleção Textos FCC, n- 29).

GATTI. B. A.; SILVA, R. N.; ESPÓSITO, Y. L. Alfabetização e educação básica no Brasil. Cadernos de Pesquisa, n. 75, p. 7-14, 1990.

GATTI, B. A. et al. Um estudo avaliativo do Programa Institucional de Bolsa de Iniciação à Docência (PIBID). Textos FCC, São Paulo, v. 41, p. 1-120, 2014.

GATTI, B. A. et al. Professores do Brasil: novos cenários de formação. Brasília, DF: Unesco, 2019.

GRUPO DE ESCOLAS MUNICIPAIS DE ENSINO FUNDAMENTAL DA CIDADE DE SÃO PAULO. Apresentação. Revista do Projeto de Valorização do Educador e Melhoria da Qualidade de Ensino - PROVE, São Paulo, ano 17, n. 17, nov. 2018.

INSTITUTO NACIONAL DE ESTUDOS E PESQUISAS EDUCACIONAIS ANÍSIO TEIXEIRA (INEP). Censo da Educação Superior. Sinopse Estatística - 2018. Disponível em: http://www.portal.inep.gov.br/ web/guest/sinopsesestatisticas. Acesso em: 08 dez. 2019.

IZA, D. F. V.; SOUZA NETO, S. Por uma revolução na prática de ensino: o estágio curricular supervisionado. Curitiba: CRV, 2015.

KRONBAUER, S. C. G.; SIMIONATO, M. F. (org.). Articulando saberes na formação de professores. São Paulo: Paulinas, 2012.

MAINARDES, J. Abordagem do ciclo de políticas: uma contribuição para análise de políticas educacionais. Educação e Sociedade, v. 27, n. 94, p. 47-69, 2006.

MARTINS, M. C.; MOMOLI, D.; BONCI, E. (org.). Formação de educadores: modos de pensar e provocar encontros com a arte e mediação cultural. São Paulo: Terracota, 2018.

MARTINS, J. A.; ZAPPONE, M. H. Y. (org.). Formação docente: percursos e reflexões a partir do PIBIDUEM. Maringá, PR: EDUEM, 2018.

MOACYR, Primitivo. A instrução e as províncias: subsídios para a história da educação no Brasil, 1835-1889. Vol. 2. São Paulo: Companhia Editora Nacional, 1940.

NORBERG, M. (org.). Formação em contextos de estágios e desenvolvimento profissional. São Leopoldo, RS: OIKOS, 2017. 
PAPI, S. O. G.; MARTINS, P. L. O. As pesquisas sobre professores iniciantes: algumas aproximações. Educação em Revista, v. 26, n. 3, p. 39-56, 2010.

PASSOS, L. F. (org.) Formação de formadores e cursos de licenciatura: contextos, práticas e pesquisas. Campinas, SP: Pontes, 2018.

PIMENTA, S. G. A. et al. Os cursos de licenciatura em pedagogia: fragilidades na formação inicial do professor polivalente. Educação \& Pesquisa, , v. 43, n. 1, p.15-30, mar. 2017.

RAMOS, A.; HOFFMANN, P. R. P.; RAZZERA, G. Projeto IMAGINE: formando educadores para uma docência multicultural, inclusiva e inovadora. Textos FCC, São Paulo, v. 57, p. 9-25, 2019.

RUAS, P. A. A. R. Práticas inclusivas no ensino de ciências. Textos FCC, São Paulo, v. 53, p. 132-178, 2017.

SANCHES, E. M. B. C. C. S.; PASSARELLI, L. G. (org.). Formando formadores para a escola básica do século XXI: relatos de pesquisa III. Campinas, SP: Pontes, 2019.

SARTI, F. M. Parceria intergeracional no estágio supervisionado de prática de ensino e o valor da experiência docente na formação de novos professores. In: PIOKER-HARA, F. C.; GURIDI, V.
M. (org.). Experiências de ensino nos estágios obrigatórios: uma parceria entre a universidade e a escola. Campinas, SP: Alínea, 2013. p. 107-122.

SILVA, F. O.; RIOS, J. A. V. P. (org.). Iniciação à docência na educação básica: experiências formativas no PIBID. Salvador: EDUNEB, 2019.

TANURI, L. M. História da formação de professores. Revista Brasileira de Educação, n. 14, p. 61-88, 2000 .

UMBELLINO, M. M.: CIRÍACO, K. T. "Dores, dilemas e descobertas": desafios de professores iniciantes na carreira do magistério. Momento: Diálogos em Educação, v. 27, n. 1, p. 399-425, 2018.

VASCONCELOS, M. Apresentando a obra. In: VASCONCELOS, M.; ANDRADE, V. C. de. Formação de professores e projetos interdisciplinares: perspectiva para uma outra escola. Curitiba: Brazil Publishing, 2019. p. 1-5.

VASCONCELOS, M.; ANDRADE, V. C. de. Formação de professores e projetos interdisciplinares: perspectiva para uma outra escola. Curitiba: Brazil Publishing, 2019.

Recebido em: 19/12/2019

Aprovado em: 23/02/2020 